\title{
EVALUATION OF PERI-IMPLANT AND POSTERIOR BONE LOSS IN RIGID VERSUS NON-RIGID TELESCOPIC ATTACHMENTS IN TWO-IMPLANT SUPPORTED MANDIBULAR OVERDENTURE
}

\author{
Diana Khalil Khalil*, Emad Mohammed Agamy** and Gihan Fekry Mohammed ${ }^{* * *}$
}

\begin{abstract}
Aim: The purpose of the study was to evaluate peri-implant and posterior bone loss in rigid and non- rigid telescopic two-implant supported mandibular overdenture.

Materials and Methods: 12 completely edentulous patients received two mandibular interforaminal implants to retain telescopic overdenture with metal band inserted beneath the first molar tooth bilaterally, opposed by maxillary complete denture. Group I (6 patients) had rigid telescopic connection and group II (6 patients) received non-rigid telescopic attachments. Radiographic evaluation was made after one year of using the overdenture to assess peri-implant and posterior bone loss using standardized periapical long cone parallel technique.

Results: there was no statistical significant difference regarding peri-implant bone loss between the two groups. On the other hand, there was statistical significant difference in posterior bone loss being higher in the non-rigid group.

Conclusion: telescopic two-implant mandibular overdenture showed great success and acceptance among patients, no implant failure or screw loosening occurred during one year using the overdenture, bone loss was in the accepted values. Within the limitations of this study, rigid telescopes can be used on two implants to retain mandibular overdenture opposed by maxillary complete denture.
\end{abstract}

KEY WORDS: Two-implant mandibular overdenture, telescopic overdenture, rigid telescopic, non-rigid telescopic, bone loss

\section{INTRODUCTION}

Complete edentulism has many devastating effects on every aspect in patient's life. The introduction of osseointegrated implants brought hope to patients and enhanced the prosthodontic society to consider two-implant supported mandibular overdenture to be the minimum treatment offered to those patients ${ }^{(1,2)}$.

\footnotetext{
* Assistant Lecturer of Prosthodontics, Faculty of Dentistry, Fayoum University.

** Professor of Prosthodontics and Vice Dean for Education and Student Affairs, Faculty of Dentistry, Minia University *** Professor of Prosthodontics and Vice President, Kantara University
} 
Several attachment systems used to connect the overdenture to the implants as ball anchors, magnets, locator, bar, and telescopic attachments. The choice of the suitable type of attachments is dependent on many factors as the amount of retention needed, interarch space, arch morphology, manual dexterity of the patient, and skills of the dentist (3). There is no evidence based data on the ideal implants number for retaining mandibular overdenture ${ }^{(4)}$, Celik et al. 2014 stated that the number of implants had no significant effect on peri-implant stress values when applying axial load ${ }^{(5)}$. The choice of splinting implants using bar attachment is favored by some authors for better stress distribution ${ }^{(6,7,8)}$. In a systematic literature review by Stoumpis et al. 2011 comparing between splinted and non-splinted implants for a minimum of three years follow-up period; no difference was found regarding implant survival or peri-implant parameters ${ }^{(9)}$. Plaque accumulation, gingival inflammation, and periimplant bone loss, in addition to speech difficulties and narrowing of tongue space experienced more in patients treated with bar than with telescopic attachment mandibular overdenture ${ }^{(10)}$.

Telescopic attachments are composed of primary coping permanently cemented on the tooth or implant abutment and secondary coping picked up in the fitting surface of the overdenture. Retention is produced from friction between the two copings; the degree of taper is inversely proportionate with the retention and the parallel-wall design with zero degree taper produce better retention. Telescopic attachments provide horizontal stability because of their parallel-wall design, adequate retention, self-seated and easily cleaned by the patients. They are subdivided into rigid and non-rigid types; rigid type has intimate contact with no space between the primary and secondary copings with definite end position in the primary coping. The non-rigid type has occlusal space about $0.3-0.5 \mathrm{~mm}$ to compensate for the mucosal resiliency of the denture bearing area and circumferential or axial space of $0.03-0.05 \mathrm{~mm}$ to release stresses on the implant, also there is no end position on the primary copings ${ }^{(11)}$.
Heckmann et al. found that implant strain and denture-bearing area loading values were conversely related, and were dependent on the rigidity of the connector used and the thickness and resiliency of the underlying soft tissue. They found that the rigid telescopic attachments on two-implant supported overdenture produced massive stresses on the implants five times larger than the non-rigid type that may lead to implant fracture; on the other hand it had the lowest strain on the posterior edentulous area. The opposite produced with the non-rigid type, lowest stresses on the implants and high on the posterior area ${ }^{(12)}$.

The aim of the study was to evaluate peri-implant bone loss and posterior bone loss after one year of using rigid versus non-rigid telescopic attachments in two-implant supported mandibular overdenture.

\section{MATERIALS AND METHODS}

After approval from the research ethics committee, faculty of dentistry, Minia University, Egypt no. 299, September 2018; the study was conducted on twelve completely edentulous patients who signed informed consent. The patients approved to participate in the study after thorough explanation of its purpose, steps and every possible complication.

All included patients were completely edentulous, having normal maxilla-mandibular relation Angle class I, tentative jaw relation was made to ensure adequate interarch space about $14 \mathrm{~mm}$ for telescopic overdenture construction. Patients were free from any systemic diseases that may interfere with bone healing as diabetes mellitus, glycosylated haemoglobin test (HBA1C) was done and patients included were having results beneath $6.5 \%$ (not diabetic nor prediabetic). Heavy smoker patients were excluded from the study. Preoperative panoramic $\mathrm{x}$-ray was made for all patients to evaluate bone height, detect any pathological lesions or remaining roots.

All patients received complete denture with metal chip or band incorporated beneath the mandibular 
first molar bilaterally, then the mandibular denture was duplicated into transparent acrylic resin radiographic stent. This stent was fitted with gutta-percha attached to the labial and buccal surface for cone beam computed topography of the mandibular arch. After detecting the best implant locations for each patient, the radiographic stent was transformed into surgical stent by drilling a hole in the lingual side opposite to the planned osteotomy site. Drilling was carried over through this stent by the pilot and first drill then the osteotomy site was completed freehand after removing the stent. Patients were asked to rinse with $0.12 \%$ chlorhexidine digluconate 15 minutes prior to surgery; crestal mucoperiosteal envelop flap was made from the left second premolar to the right one. Every patient received two interforaminal implants 3.5 to $4 \mathrm{~mm}$ diameter and $11.5 \mathrm{~mm}$ length (Neobiotech Co., Seoul, Korea) (Figure 1); the implants were covered and left for 3 months of uninterrupted healing. The surgical procedure was done under prophylactic antibiotic coverage.

Patients were randomly allocated into two groups. Randomization was done by putting the patients in order of receiving the implants first and giving them numbers, odd numbers were categorized as the first group and even numbers as the second group. After three months of osseointegration, implants were uncovered with a scalpel by the aid of the surgical stent to detect them, impression copings were screwed and closed tray impression was made using putty and light body addition silicon (a-silicon impression material, Zhermack S.P.A. 45021 Badia Polesine (Rovigo) Italy) (Figure 2), the impression copings were removed and implant analogues were tightened to them and inserted in their places in the impression. The first group had rigid telescopic attachments and the second group received non-rigid telescopes, straight titanium implant abutments were used as the primary copings after milling them to have parallel walls and $5 \mathrm{~mm}$ in length with the use of dental parallelometer (Figure $3)$. For both groups a duralay verification jig was made to transfer the exact abutments position on the implants (Figure 4). Secondary titanium copings were milled by CAD/CAM system (smart optics Vinyl scanner, exocad software, Emar ED5X milling machine) for accurate manufacturing (Figures 5,6). These copings had metal tags for retention into the denture base. Direct pick-up of secondary copings was done in the patient mouth using methyl methaacrylate monomer free chair side self-curing rebase material (Tokuyama Rebase II Fast, Tokuyama Dental Corporation, Japan) (Figure 7).

Standardized periapical long cone parallel technique (Figure 8) was used for evaluation of peri-implant bone loss. The bone level was measured from the implant shoulder as the reference point and first bone to implant contact mesially and distally. To measure the posterior bone loss in the edentulous area; the bone level was measured from the middle of the metal chip perpendicular to the crest of the ridge.

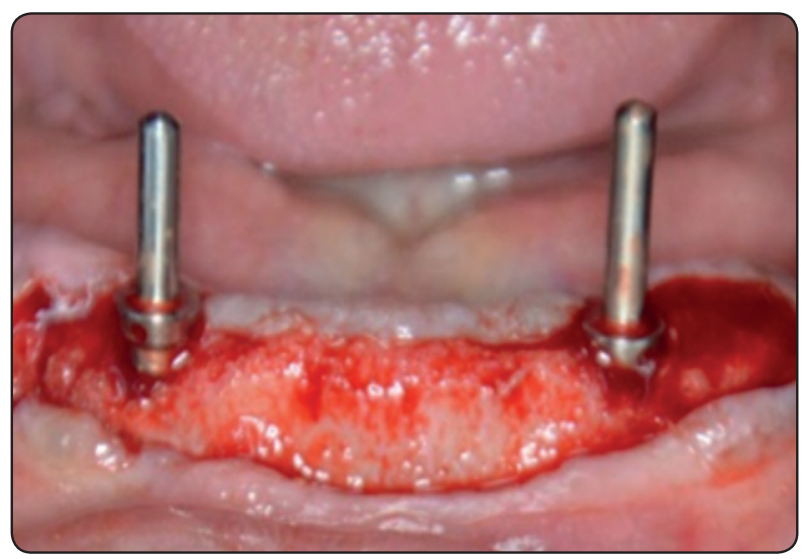

Fig. (1) Parallel guiding pins

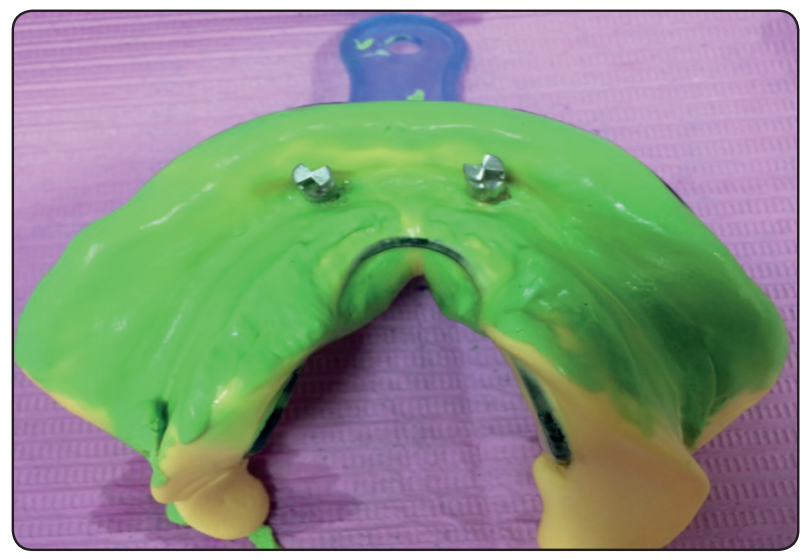

Fig. (2) Addition silicon closed tray impression technique for the implants 


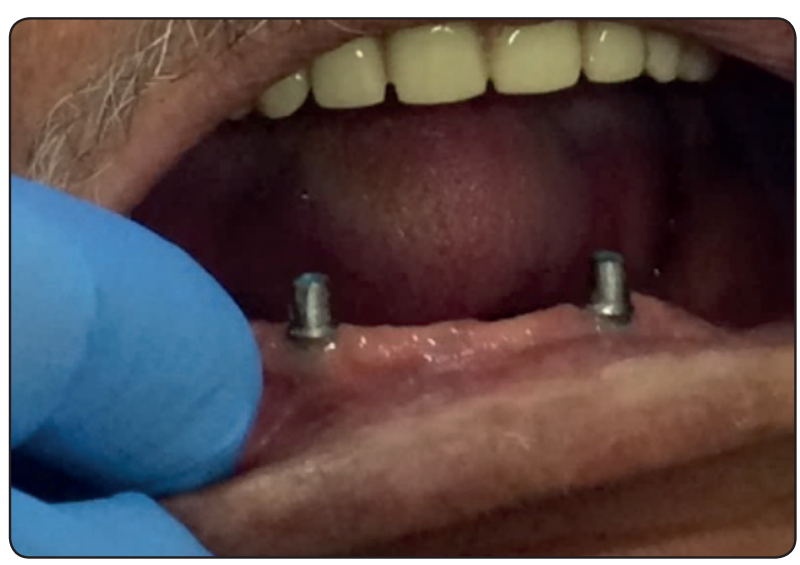

Fig. (3) Parallel milled abutments used as primary copings

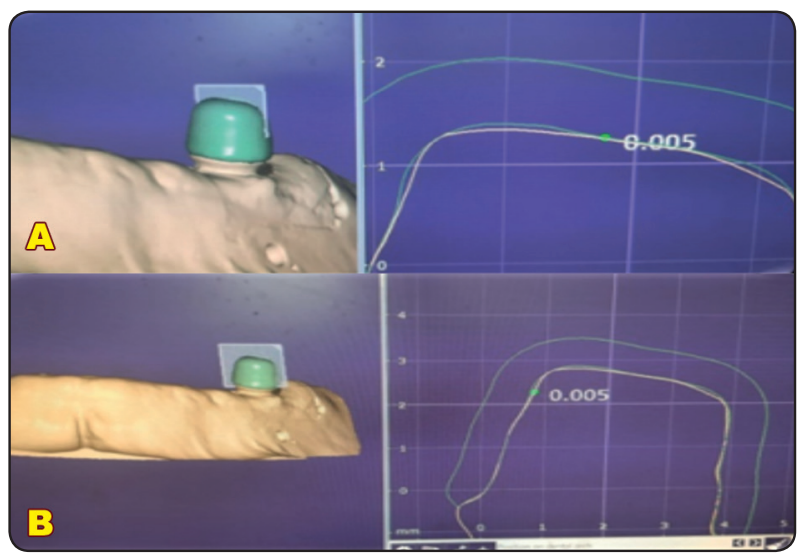

Fig. (5) (a,b). CAD/CAM designing secondary copings for rigid telescopic attachments

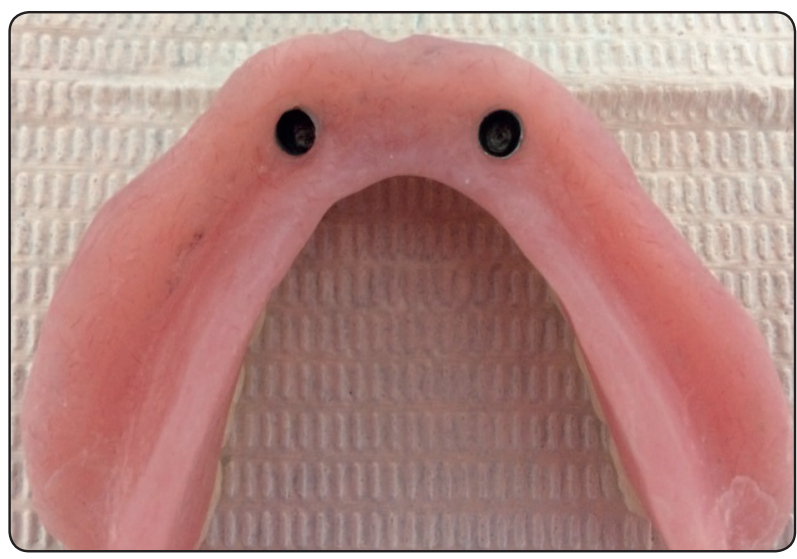

Fig. (7) Direct pick-up for secondary copings

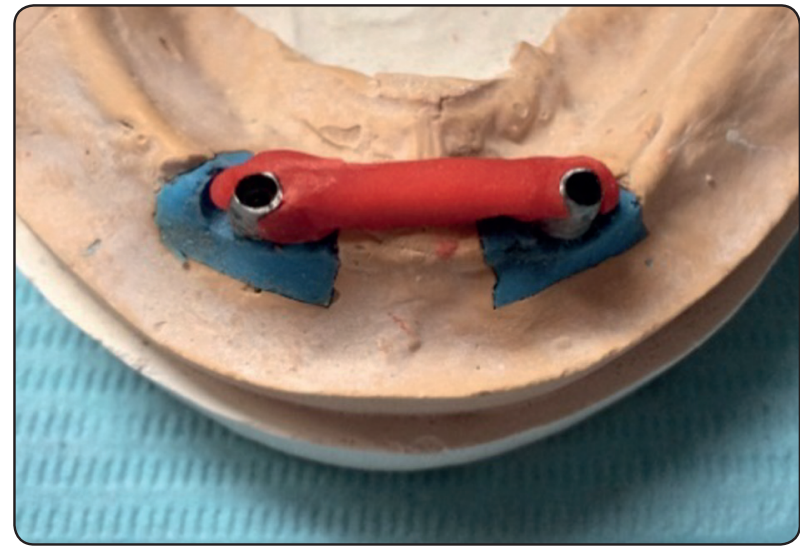

Fig. (4) Duralay verification jig

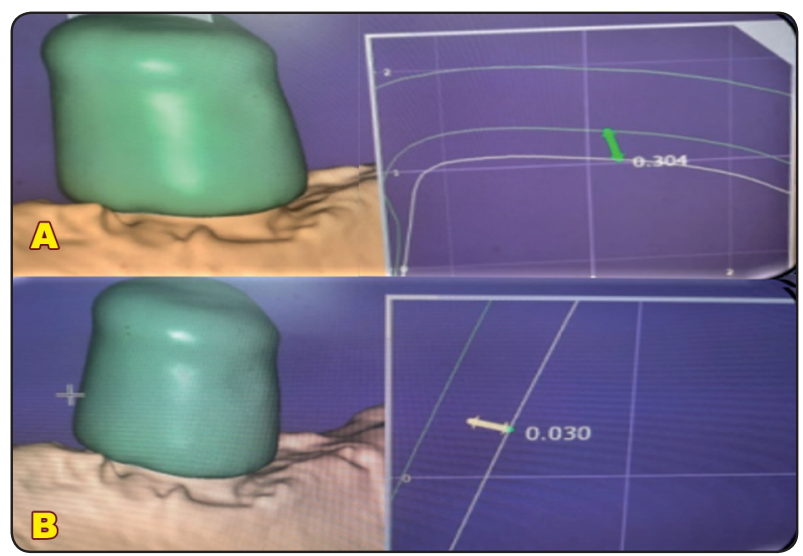

Fig. (6) (a,b). CAD/CAM designing secondary copings for nonrigid telescopic attachments

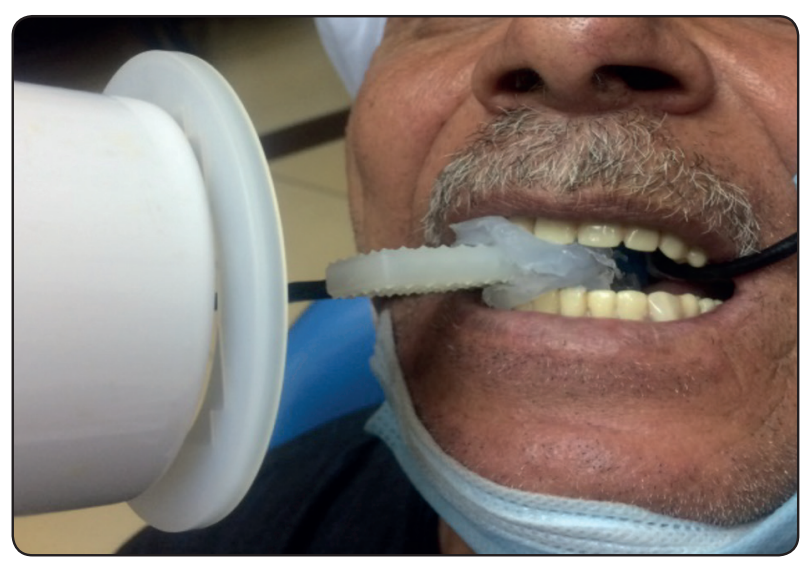

Fig. (8) Standardized long cone parallel technique periapical x-ray 


\section{RESULTS}

Mean mesial bone loss after one year of using the overdenture was $0.37 \pm 0.23$ in the rigid telescopic group and $0.45 \pm 0.12$ in the non-rigid group with no significant statistical difference; for mean distal bone loss, both groups recorded almost the same results, $0.42 \pm 0.16$ in the rigid group and $0.43 \pm 0.16$ in the non-rigid group with no significant statistical difference. The average peri-implant bone loss after one year was $0.39 \pm 0.13$ and $0.44 \pm 0.14$ for the rigid and non-rigid telescopes respectively with no significant difference between peri-implant bone losses in both groups (table 1).

Mean posterior bone loss was $0.41 \pm 0.13$ in the rigid group and $0.63 \pm 0.12$ in the non-rigid group with $\mathrm{p}$ value $<0.001$ and statistically significant difference between the two groups, after one year of using the overdenture (table 2).

TABLE (1) Peri-implant bone loss

\begin{tabular}{|c|c|c|c|c|}
\hline Change in average bone loss & Group I $(n=12)$ & Group II $(n=12)$ & $\mathbf{U}$ & $\mathbf{P}$ \\
\hline \multicolumn{5}{|l|}{ [12 months - Baseline] } \\
\hline Min. - Max. & $0.20-0.66$ & $0.29-0.70$ & \multirow{2}{*}{54.0} & \multirow{2}{*}{0.319} \\
\hline Mean \pm SD & $0.39 \pm 0.13$ & $0.44 \pm 0.14$ & & \\
\hline Change in mesial bone loss & Group I $(n=12)$ & Group II $(n=12)$ & $\mathbf{U}$ & $\mathbf{P}$ \\
\hline \multicolumn{5}{|l|}{ [12 months - Baseline] } \\
\hline Min. - Max. & $0.12-0.92$ & $0.25-0.70$ & \multirow[t]{2}{*}{41.0} & \multirow[t]{2}{*}{0.078} \\
\hline Mean \pm SD & $0.37 \pm 0.23$ & $0.45 \pm 0.12$ & & \\
\hline Change in distal bone loss & Group I $(n=12)$ & Group II $(n=12)$ & $\mathbf{U}$ & $\mathbf{P}$ \\
\hline \multicolumn{5}{|l|}{ [12 months - Baseline] } \\
\hline Min. - Max. & $0.16-0.67$ & $0.20-0.70$ & 71.50 & 0.977 \\
\hline Mean \pm SD & $0.42 \pm 0.16$ & $0.43 \pm 0.16$ & & \\
\hline
\end{tabular}

IQR: Inter quartile range

SD: Standard deviation

U: Mann Whitney test

p: p value for comparing between the studied groups

*: Statistically significant at $p \leq 0.05$

TABLE (2) Posterior bone loss

\begin{tabular}{|c|c|c|c|c|}
\hline Change in posterior bone loss & Group I (n= 12) & Group II (n= 12) & t & P \\
\cline { 1 - 3 } [12 months - Baseline] & \multirow{3}{*}{$4.285^{*}$} & $<0.001^{*}$ \\
\hline Min. - Max. & $0.18-0.60$ & $0.45-0.90$ & $0.63 \pm 0.12$ & \\
\hline Mean \pm SD. & $0.41 \pm 0.13$ &
\end{tabular}

IQR: Inter quartile range

SD: Standard deviation

t: Student t-test

p: $p$ value for comparing between the studied groups $\quad *$ : Statistically significant at $p \leq 0.05$ 


\section{DISCUSSION}

Two-implant supported mandibular overdenture had gained popularity over the conventional complete denture due to the recorded patient satisfaction, improved quality of life and better retention and stability of the mandibular denture. Interforaminal area in the mandible is one of the best areas for implant placement for its good bone quality in addition to the absence of vital structures which allow the use of longer implants if there is enough bone $\mathrm{e}^{(10,13,14)}$

Although diabetes and smoking are not absolute contraindication for implant placement, they are associated with higher failure rate because they affect healing due to accompanied reduced blood supply ${ }^{(15-17)}$, for standardization purpose and to avoid any confounding factor may affect bone resorption other than type of attachments, those criteria were excluded from the study.

There are many attachment systems available for implant overdenture, one of them is telescopic attachment which was successfully used for many years with remaining natural teeth and used with implants with reported higher success rate ${ }^{(18,19)}$.

Telescopic overdenture adds stability to the prosthesis in addition to the retention gained by friction between the primary and secondary copings. It is also characterized by its self-seating criteria which is advantageous especially with old patients and those with reduced dexterity plus it is easier to kept clean by the patient thus less plaque retention and peri-implant inflammation ${ }^{(10,20-25)}$. Direct pickup of the secondary copings were done because it is easier and more precise ${ }^{(26)}$.

Bone loss was measured using standardized periapical long cone parallel technique which is considered the "gold standard" to visualize even minute changes ${ }^{(27,28)}$. Although CBCT can detect complete peri-implant bone loss not just proximal as in periapical $\mathrm{x}$-ray, but there is possible artifact occur around metal object as in implants may affect recording accurate results ${ }^{(29)}$, also it is unethical to expose the patient to unnecessary radiation dose in all follow-up sessions in addition to the preoperative one.

Few clinical studies used rigid two-implant telescopic mandibular overdenture ${ }^{(6,10,30)}$, although not reporting significant complications or periimplant bone loss. Some studies did not recommend its use with two implants and reported high stress which may lead to implant fracture ${ }^{(12,31)}$, and recommended the use of non-rigid type for two implants and the rigid type should be used with four implants. But most of these studies were done on models using force transducers or strain gauges.

The current study tried to standardize the loading factors as much as possible in a clinical set up to provide a unique viable comparison of this field. The current study compared clinically the peri-implant bone loss between the rigid and non-rigid telescopic attachment used with two-implant supported mandibular overdenture opposed by maxillary complete denture to standardize the occlusal load. After one year of using the overdenture there was no statistical significant difference between the two groups. None of the patients in both groups reported any implant loss, fracture, screw loosening or any other complications. This was in accordance to Eitner et al. 2008 who found no radiographic difference between the telescopic and bar and Cepa et al. 2017 who found no difference radiographically between the non-rigid ball and rigid telescopic twoimplant mandibular overdenture ${ }^{(10,30)}$.

Metal chip or band was incorporated beneath the mandibular first molar bilaterally to demarcate the area for residual ridge bone loss evaluation. This area was selected as it is considered to bear the largest amount of occlusal load where there is maximum contraction of all elevator muscles ${ }^{(32)}$. Regarding posterior bone loss, there was significant difference between the two groups with bone loss 
higher in the non-rigid group. This is in agreement with Heckmann et al. ${ }^{(12)}$, who explained such finding to be due to the movement of the denture during function in the non-rigid group, this movement causes bone resorption posteriorly with time and releases strain on the implants.

\section{CONCLUSION}

Within the limitations of this study, rigid telescopes can be used successfully with two-implant supported mandibular overdenture. More clinical studies should be done on larger patient group and longer follow-up period to compare between the rigid and non-rigid groups regarding retention, periimplant tissue condition, patient satisfaction, and to verify the use of rigid telescopes with two-implant mandibular overdenture.

\section{Conflict of Interest}

The authors declared no conflicts of interest related to this study.

\section{Funding}

The study was self-funded by the authors.

\section{Contribution}

All authors had read the manuscript, revised and approved it.

\section{REFERENCES}

1. Feine JS, Carlsson GE, Awad MA, et al. The McGill consensus statement on overdentures. Mandibular twoimplant overdentures as first choice standard of care for edentulous patients. Gerodontology 2002;19:3-4.

2. Thomason JM, Feine J, Exley C, et al. Mandibular two implant-supported overdentures as the first choice standard of care for edentulous patients-the York Consensus Statement. Br Dent J 2009;207:185-186.

3. Alqutaibi AY, Kaddah AF. Attachments used with implant supported overdenture. Int Dent Med J Adv Res 2016;2:1-5.

4. Klemetti E. Is there a certain number of implants needed to retain an overdenture? J Oral Rehabil 2008;35:80-84.
5. Celik G, Uludag B. Effect of the Number of Supporting Implants on Mandibular Photoelastic Models with Different Implant-Retained Overdenture Designs. J Prosthodont 2014;23:374-380.

6. Mericske-Stern R, Piotti M, Sirtes G. 3-D in vivo force measurements on mandibular implants supporting overdentures. A comparative study. Clin Oral Impl Res 1996;7:387-396.

7. Assunção W, Tabata I, Barão V, Rocha E. Comparison of stress distribution between complete denture and implant-retained overdenture-2D FEA. J Oral Rehabil 2008;35:766-774.

8. Elsyad M, Khirallah A. Circumferential bone loss around splinted and nonsplinted immediately loaded implants retaining mandibular overdentures: A randomized controlled clinical trial using cone beam computed tomography. J Prosthet Dent 2016;116:741-748.

9. Stoumpis C, Kohal RJ. To splint or not to splint oral implants in the implant-supported overdenture therapy. A systematic literature review. J Oral Rehabil. 2011;38:857-869.

10. Eitner S, Schlegel A, Emeka N, Holst S, Will J, Hamel J. Comparing bar and double-crown attachments in implantretained prosthetic reconstruction: a follow-up investigation. Clin Oral Implants Res 2008;19:530-537.

11. Langer A. Telescope retainers and their clinical application. J Prosthet Dent 1980;44:516-522.

12. Heckmann S, Winter W, Meyer M, Weber H, Wichmann M. Overdenture attachment selection and the loading of implant and denture-bearing area. Part 2: A methodical study using five types of attachment. Clin Oral Implants Res 2001;12:640-647.

13. Misch CE. Dental implant prosthetics. St Louis, Missouri: Elsevier Mosby; 2005. ISBN 0-323-01955-2.

14. Kim HJ, Yu SK, Lee MH, Lee HJ, Kim HJ, Chung CH. Cortical and cancellous bone thickness on the anterior region of alveolar bone in Korean: A study of dentate human cadavers. J Adv Prosthodont. 2012;4:146-152.

15. Loo W, Jin L, Cheung M, Wang M. The impact of diabetes on the success of dental implants and periodontal healing. Afr J Biotechnol 2009; 8:5122-5127.

16. Chrcanovic B, Albrektsson T, Wennerberg A.Smoking and dental implants: A systematic review and meta-analysis. J Dentist 2015;43:487-498. 
17. Naseri R, Yaghini J, Feizi A. Levels of smoking and dental implants failure: A systematic review and meta-analysis. J Clin Periodontol 2020;47:518-528.

18. Verma R, Joda T, Brägger U, Wittneben JG. A Systematic Review of the Clinical Performance of Tooth-Retained and Implant-Retained Double Crown Prostheses with a FollowUp of $\geq 3$ Years. Journal of Prosthodontics 2013;22:2-12.

19. Seo J, Cho J. Clinical outcomes of rigid and non-rigid telescopic double-crown-retained removable dental prostheses: An analytical review. J Adv Prosthodont 2020;12: $38-48$.

20. Heckmann S, Heckmann J, Weber H. Clinical outcomes of three Parkinson's disease patients treated with mandibular implant overdentures. Clin Oral Implants Res 2000;11:566-571.

21. Heckmann S, Schrott A, Graef F, Wichmann M, Weber H. Mandibular two-implant telescopic overdentures. Clin Oral Implants Res 2004;15:560-569.

22. Hoffmann O, Beaumont C, Tatakis DN, Zafiropoulos GG. Telescopic crowns as attachments for implant supported restorations: a case series. J Oral Implantol 2006;32:291299.

23. Krennmair G,Weinländer M,Krainhöfner M, Piehslinger E. Implant supported mandibular overdentures retained with ball or telescopic crown attachments: A 3-year prospective study. Int J Prosthodont 2006;19:164-170.

24. Krennmair G, Seemann R, Weinlander M, Piehslinger E. Comparison of ball and telescopic crown attachments in implant-retained mandibular overdentures: a 5-year prospective study. Int J Oral Maxillofac Implants 2011; 26:598-606.
25. Khairallah A, Shawky A. Milled bar versus rigid telescopic attachment for mandibular implant supported overdentures. A study of patient satisfaction and oral health quality of life. Egypt Dent J 2020;66:1183-1193.

26. Nissan J, Oz-Ari B, Gross O, Ghelfan O, Chaushu G. Long-term prosthetic aftercare of direct vs. indirect attachment incorporation techniques to mandibular implant-supported overdenture. Clin Oral Impl Res 2011;22:627-630.

27. Verhoeven J, Cune M, Putter C. Reliability of some clinical parameters of evaluation in implant dentistry. Journal of Oral Rehabilitation 2000;27:211-216.

28. De Smet E, Jacobs R, Gijbels F, Naert I. The accuracy and reliability of radiographic methods for the assessment of marginal bone level around oral implants. Dentomaxillofac Radiol 2002;31:176-181.

29. Razavi T, Palmer RM, Davies J, Wilson R, Palmer PJ. Accuracy of measuring the cortical bone thickness adjacent to dental implants using cone beam computed tomography. Clin Oral Impl Res 2010;21:718-725.

30. Cepa S, Koller B, Spies BC, Stampf S, Kohal RJ. Implant-retained prostheses: ball vs. conus attachments - A randomized controlled clinical trial. Clin Oral Impl Res 2017;28:177-185.

31. Hegazy S, Gebreel A, Emera R. Resilient versus rigid telescopic attachment for two implants assisted complete mandibular overdentures: invitro stress analysis study. Egypt Dent J 2014;60:725-732.

32. Sadowsky SJ, Caputo A A. Effect of anchorage systems and extension base contact on load transfer with mandibular implant-retained overdentures. J Prosthet Dent 2000;84:327-334. 